\title{
Physiological and Anatomical Studies of the Interactions Between Purkinje Cells and Basket Cells in the Cat's Cerebellar Cortex: Evidence for a Unitary Relationship
}

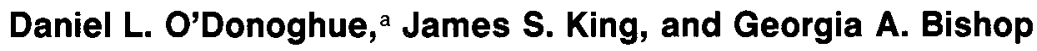 \\ Department of Anatomy and Neuroscience Program, The Ohio State University, Columbus, Ohio 43210
}

\begin{abstract}
Intracellular recordings have been obtained from neurons in lobule $V$ of the cat's vermis, which were identified as basket cells following intracellular injections of HRP. Stimulation of the inferior cerebellar peduncle or peripheral nerves elicited an initial depolarizing and subsequent hyperpolarizing response. Neither potential could be graded with changes in stimulus intensity; both displayed all-or-none properties at threshold levels of stimulation. The depolarization and hyperpolarization were confirmed as an excitatory postsynaptic potential and an inhibitory postsynaptic potential (IPSP), respectively, on the basis of their response to intracellular injections of hyperpolarizing and depolarizing currents into the cell body.
\end{abstract}

A possible source of the unitary IPSP is the Purkinje cell, via its recurrent axonal collaterals. To test this hypothesis, an electron microscopic analysis was carried out to define the synaptic relationships between the recurrent collaterals of an HRP-filled Purkinje cell and 3 basket cells. Serial section analysis reveals that collaterals from a single Purkinje cell contact several basket cells, but each basket cell received somatic input from only one Purkinje cell. These data provide an anatomical substrate for the unitary IPSP observed during intracellular recording from basket cells. The unitary nature of the Purkinje cell-basket cell interaction indicates that a very limited population of cortical neurons may be involved in local circuits that integrate afferent information in the cerebellar cortex.

The contribution of the recurrent collaterals of Purkinje cells to local circuitry in the cerebellar cortex of the cat has been the subject of a number of recent reports (Bishop et al., 1980; Bishop, 1982, 1988; King and Bishop, 1982; Bishop and O'Donoghue, 1986). During the course of these experiments, neurons were impaled that had response properties distinct from the climbing fiber responses evoked in Purkinje cells following stimulation of the inferior cerebellar peduncle. Intracellular injec-

Received July 25, 1988; revised Nov. 2, 1988; accepted Nov. 4, 1988.

This work was supported by Grants NIH 07814 and NSF 8505971 . The technical skills of Katharine Dillingham and Barbara Diener-Phelan are greatly appreciated. We thank Dr. Brad Stokes for reading the manuscript and offering helpful editorial suggestions. We also thank Mr. Karl Rubin for photographic assistance.

Correspondence should be addressed to Georgia A. Bishop, Ph.D., Department of Anatomy, The Ohio State University, 333 W. 10th Avenue, Columbus, $\mathrm{OH}$ 43210 .

a Present address: Department of Physiology, Emory University, School of Medicine, Atlanta, GA 30322.

Copyright (C) 1989 Society for Neuroscience $0270-6474 / 89 / 062141-10 \$ 02.00 / 0$ tions of these units with HRP revealed that the responses were obtained from basket cells.

Basket cells are interneurons that are located in the lower molecular layer of the cerebellar cortex (Fox et al., 1967; Mugnaini, 1972; Palay and Chan-Palay, 1974). Their somata are interspersed between and within the dendritic trees of Purkinje cells (Fox et al., 1967; Palay and Chan-Palay, 1974); their dendrites extend toward the pial surface, and their axons are primarily oriented in the sagittal plane. Descending collaterals of these axons form a unique pericellular basket around the somata and axon hillocks of Purkinje cells, defined as the pinceau by Ramón y Cajal (1911).

Physiological studies on basket cell output (Eccles et al., 1967; Bloedel and Roberts, 1969, 197 I; Llinás and Precht, 1969; Bloedel et al., 1972) have shown that they inhibit Purkinje cells. On the basis of field potential and extracellular unit analysis, basket cells are thought to be inhibited by the axon collaterals of Purkinje cells and excited by both parallel fibers and collaterals of climbing fibers (Eccles et al., 1967; Bloedel and Roberts, 1969, 1971; Llinás and Precht, 1969; Bloedel et al., 1972). However, the characteristics of these responses have not been previously analyzed with intracellular recording techniques.

In the present study, intracellular recording and staining techniques were used to analyze the physiological characteristics of identified basket cells. The data indicate that these interneurons respond with an initial low-amplitude depolarization followed by a powerful hyperpolarization after stimulation of the inferior cerebellar peduncle; both responses appear to be unitary in nature. The anatomical substrate for the unitary inhibitory input was identified as Purkinje cells, which were shown to have a one-to-one synaptic relationship with basket cells.

\section{Materials and Methods}

Adult cats were anesthetized with a combination of sodium thialymyl (Surital; $35 \mathrm{mg} / \mathrm{kg}$, i.p.) and alpha-chloralose (70 mg/kg, i.p.). Supplementary doses of chloralose were given as needed during the experiment. Bipolar stimulating electrodes were placed within the ipsilateral inferior cerebellar peduncle and bilaterally on the sciatic, ulnar, and radial nerves. The recording, injection, and stimulating paradigms are identical to those described in previous studies (Bishop and O'Donoghue, 1986; Bishop, 1988).

\section{Tissue processing}

The animals were perfused through the heart with saline followed by $2 \%$ glutaraldehyde- $2 \%$ paraformaldehyde in phosphate buffer $(\mathrm{pH} 7.4)$. The cerebellum was exposed and blocked in the sagittal plane in situ. The tissue was postfixed for $4-6 \mathrm{hr}$ and then transferred to phosphate buffer containing $15 \%$ sucrose $(12-16 \mathrm{hr})$. The tissue was then sagittally sectioned on a vibratome (for electron microscopy) or a freezing mi- 
crotome at $60 \mu \mathrm{m}$ and processed for HRP histochemistry using 3,3' diaminobenzidine tetrahydrochloride (DAB) as the chromogen. The tissue that was to be used for electron microscopic analysis, was processed as described previously (Bishop and King, 1982; King and Bishop, 1982). Frozen sections of the cerebellum were mounted on clean glass slides, dehydrated through a graded series of alcohol, cleared in xylene, and placed under coverslips.

\section{Dita analysis}

Physiological properties. During the experiment, each electrode penetration was made relative to a stereotaxically defined reference point and noted in the protocol. After the tissue was processed, the position of each intracellularly filled basket or Purkinje cell was noted. The location of filled cells was correlated with the position of a particular probe. Thus, the observed physiological responses were assigned to the cell from which they were recorded. The physiological data presented in this paper were derived from 28 units located in vermal lobule V. All 28 units had similar responses to stimulation of the inferior cerebellar peduncle. Of these 28 units, 7 were injected with HRP and their identity confirmed as basket cells (Fig. $1, A, B$ ). The remaining units had identical physiological responses and were also assumed to be basket cells.

Eleclron microscopic analysis. This portion of the study was designed to examine the synaptic relationships between terminals derived from an identified Purkinje cell and the somata of basket cells within the area encompassed by the Purkinje cell's collateral plexus. Electron microscopic observations were made from 300 serial thin sections through the labeled axonal collateral of a Purkinje cell located in the lateral vermis of lobule V. Initially, the collateral plexus of this cell was reconstructed from $60 \mu \mathrm{m}$ serial sections at the light microscopic level. Fmbedded sections containing the collateral plexus were then glued to beem capsules and sectioned on an ultramicrotome at $90 \mathrm{~nm}$. Sections were collected onto slot grids coated with Formvar and stained with lead citrate and uranyl acetate. Electron micrographs were taken on a Philips 300 microscope. Basket cells were identified on the basis of their cytological features previously described by Lemkey-Johnston and Larramendi (1968), Mugnaini (1972), and Palay and Chan-Palay (1974).

\section{Results}

\section{Physiological responses of basket cells}

The responses described in this section were obtained from neurons histologically identified as basket cells and are representative of all units from which data were obtained. Serial section reconstructions of 2 injected neurons are shown in Figure $1, A, B$. The somata of these cells, which measure approximately $15 \mu \mathrm{m}$ in diametcr, are located in the lower molccular layer, immediately above the Purkinje cell layer. The cells give rise to a horizontally directed axon from which descending collaterals arise to form a pericellular nest around the somata of subjacent Purkinje cells (Fig. 1, $A, B$, solid block arrows). In addition, fine beaded collaterals arise from the main axon (Fig. $1 A$, arrowheads) or from the descending collaterals (Fig. 1, $A$, $B$, small arrows). These cells have the morphological characteristics of basket cells (Fox et al., 1967; Palay and Chan-Palay, 1974).

The intracellular responses of the cell shown in Figure $1 A$ $(\mathrm{BC} 1)$ and Figure $1 B(\mathrm{BC} 2)$ are shown in Figure 2, $A-E$ and 2, $F-I$, respectively. These responses are representative of all 28 cells analyzed in this study. In all cells from which data were obtained, stimulation of the inferior cerebellar peduncle (ICP) initially elicits a low-amplitude, depolarization (Fig. 2, $A, B, F$, $G$ ) at an average latency of $1.8 \mathrm{msec}$ (range, $1.0-3.5 \mathrm{msec}, \mathrm{SD}$, $0.64 \mathrm{msec}$; Fig. $3 B$ ). A large-amplitude hyperpolarization (mean $10.9 \mathrm{mV}$, range, $5-26 \mathrm{mV}, \mathrm{SD}, 5.0 \mathrm{mV}$ ) occurs approximately $1 \mathrm{msec}$ after initiation of the depolarizing response. The average latency (Fig. $3 C$ ) of the hyperpolarization following ICP stimulation, is $3.4 \mathrm{msec}$ (range, $2.0-5.0 \mathrm{msec}, \mathrm{SD}, 0.79 \mathrm{msec}$ ). The hyperpolarizing potential has an average duration of $10.4 \mathrm{msec}$ (range, 4.5-14 msec; Fig. 4) and an average time to peak amplitude of $2.03 \mathrm{msec}$ (range, $0.75-3.5 \mathrm{msec}$, SD, $0.95 \mathrm{msec}$; Fig. $2, A, B, F, G)$. Neither the amplitude nor the time to peak of the depolarizing response has been measured as the succeeding hyperpolarization terminates the initial response before the peak amplitude is reached. The depolarizing and hyperpolarizing potentials are not graded with changes in stimulus intensities. At threshold (Fig. 2, $B, G$ ), both responses display all-or-none properties. Increases in the level of stimulation currents above threshold do not alter the amplitude of either response (Fig. 2, $A, F)$.

To further characterize the 2 responses, hyperpolarizing and depolarizing currents were injected into the cell through the micropipette. In general, the injected currents have little effect on the initial depolarizing response; in a few cases the amplitude of this initial response is slightly increased (Fig. 2, $B-E$ ) or decreased by injection of hyperpolarizing and depolarizing currents, respectively. We therefore tentatively conclude that the depolarizing portion of the evoked responses is an EPSP. In contrast, the hyperpolarization is affected by low-amplitude current injections. Small hyperpolarizing currents (Fig. 2, $C-E, H$ ) result in a complete reversal of the potential. Similarly, low levels of depolarizing currents (Fig. $2 I$ ) increase the amplitude of these responses. Therefore, the hyperpolarizing responses seen in basket cells are likely chemically mediated inhibitory postsynaptic potentials (IPSP).

Comparable responses are obtained in basket cells $(n=6)$ following stimulation of peripheral nerves. The initial EPSP and later IPSP demonstrate all-or-none characteristics at threshold levels of stimulation. Further, the IPSP can be altered by injections of current into the soma.

\section{Comparison of basket cell and Purkinje cell responses}

A climbing fiber response is elicited in Purkinje cells at an average latency of $2.4(\mathrm{SD}=0.1) \mathrm{msec}$ following stimulation of the ICP (Fig. 3A); this is comparable to the latency of the EPSP seen in the basket cell following stimulation of the same fiber tract (Fig. 3B, Fig. 4C1-3). These data suggest that the depolarizing response may be derived from collaterals of climbing fibers. Further, the IPSP also appears to be related to climbing fiber activation of a Purkinje cell. First, the onset of the IPSP has a latency that is comparable to the onset of the secondary spikes of the climbing fiber response (Fig. 4C1-3). Second, the duration of the IPSP is directly related to the duration of the climbing fiber response (Fig. 4, $A, B, C 1-3$ ). Figure $4 C 1-3 \mathrm{com}$ pares basket cell responses with climbing fiber responses elicited in Purkinje cells from the same experiment. Although these responses were not recorded simultaneously, they were both obtained in the same experiment from cells that were located within the vermis.

\section{Anatomical substrate for the unitary IPSP}

Several studies (Fox et al., 1967; Lemkey-Johnston and Larramendi, 1968; Mugnaini, 1972; Palay and Chan-Palay, 1974; Jeager et al., 1988) have shown that basket cells are contacted by the axonal branches of Purkinje cell collaterals. In this study, the synaptic relationships between varicosities derived from the recurrent collaterals of Purkinje cells labeled with HRP and basket cells were analyzed with the electron microscope. These synaptic contacts were quantified and characterized as to their cytological features.

Figure 5 is a camera lucida drawing of the recurrent collateral 


\section{BC1}
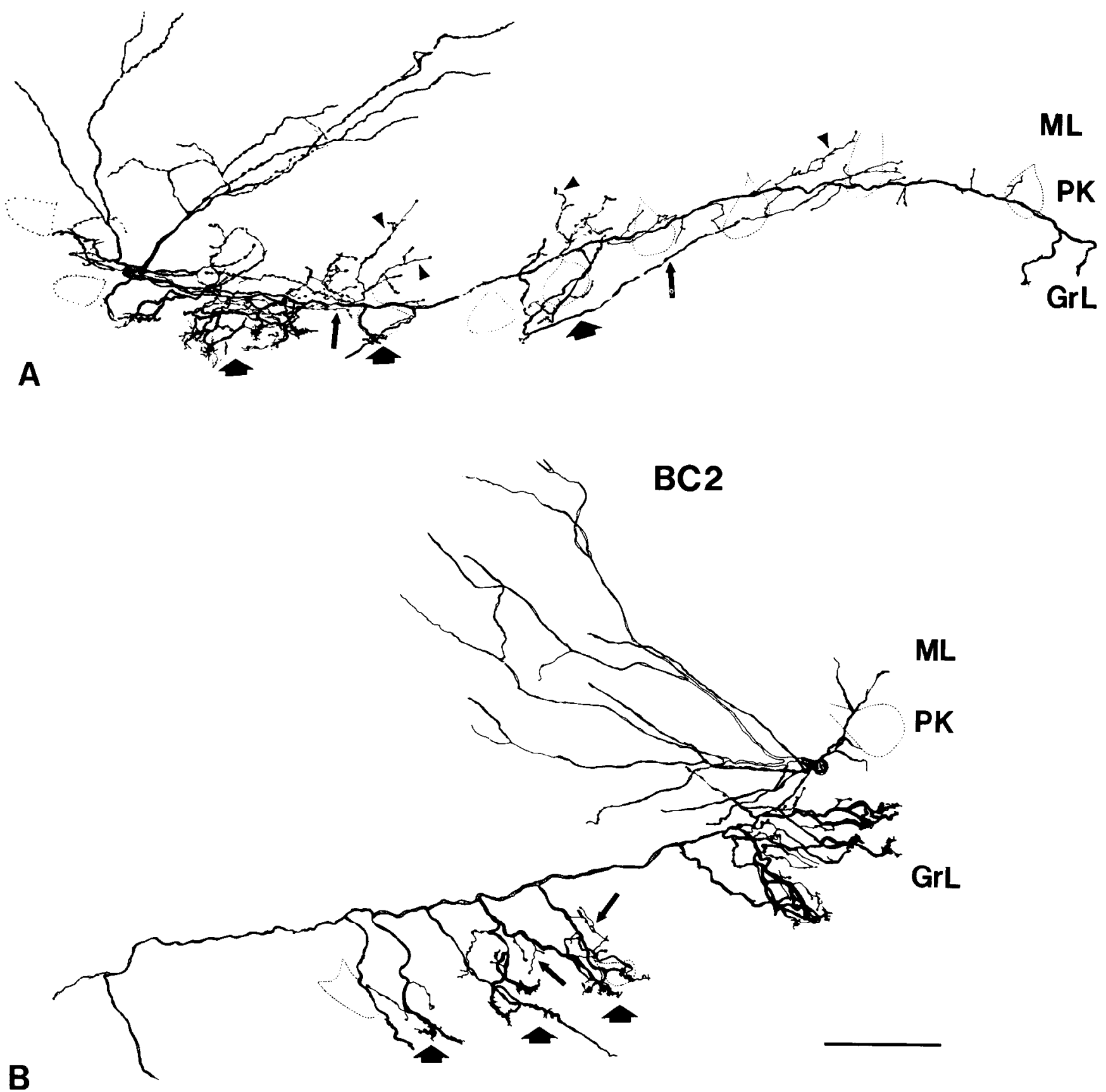

Figure 1. Serial section reconstructions of 2 basket cells $(B C 1$ and $B C 2)$ that were intracellularly injected with HRP. The solid block arrows indicate the descending collaterals of the basket cell axon that form the pinccau around the Purkinje cell body. The arrowheads in $A$ indicate beaded collaterals that arise from the main axon. The small arrows indicate beaded collaterals that arise from the axonal branches that form the pinceau $(A, B)$. The physiological responses of these 2 cells are shown in Figure 2. Scale bar, $100 \mu \mathrm{m}$. $G r L$, granule cell layer; $M L$, molecular layer; $P K$, Purkinje cell layer.

plexus of a Purkinje cell intracellularly labeled with HRP and serially reconstructed from $60 \mu \mathrm{m}$ sections. The recurrent collaterals of this cell distribute primarily to the Purkinje cell layer in the vicinity of the cell of origin. In addition, 2 branches (Fig. 5 , open block arrows) cross the folium and terminate in either the lower molecular layer (Fig. 5, curved arrow 3) or the Purkinje cell layer.

Varicosities within the collateral plexus (Fig. 5, curved arrows
1-3) form axosomatic synapses with 3 different basket cells. The relationships between the portion of the collateral plexus indicated by curved arrows 1 and 2 in Figure 5 are shown in Figures 6 and 7 , respectively. Figures $6 A$ and $7 A$ are low-power electron micrographs that illustrate the relationship of the terminals derived from the labeled recurrent collaterals of a single Purkinje cell to the somata of 2 basket cells. The labeled Purkinje cell terminals (Figs. $6, A-D, 7, A-C$ ) range in size from 0.7 to 2.26 

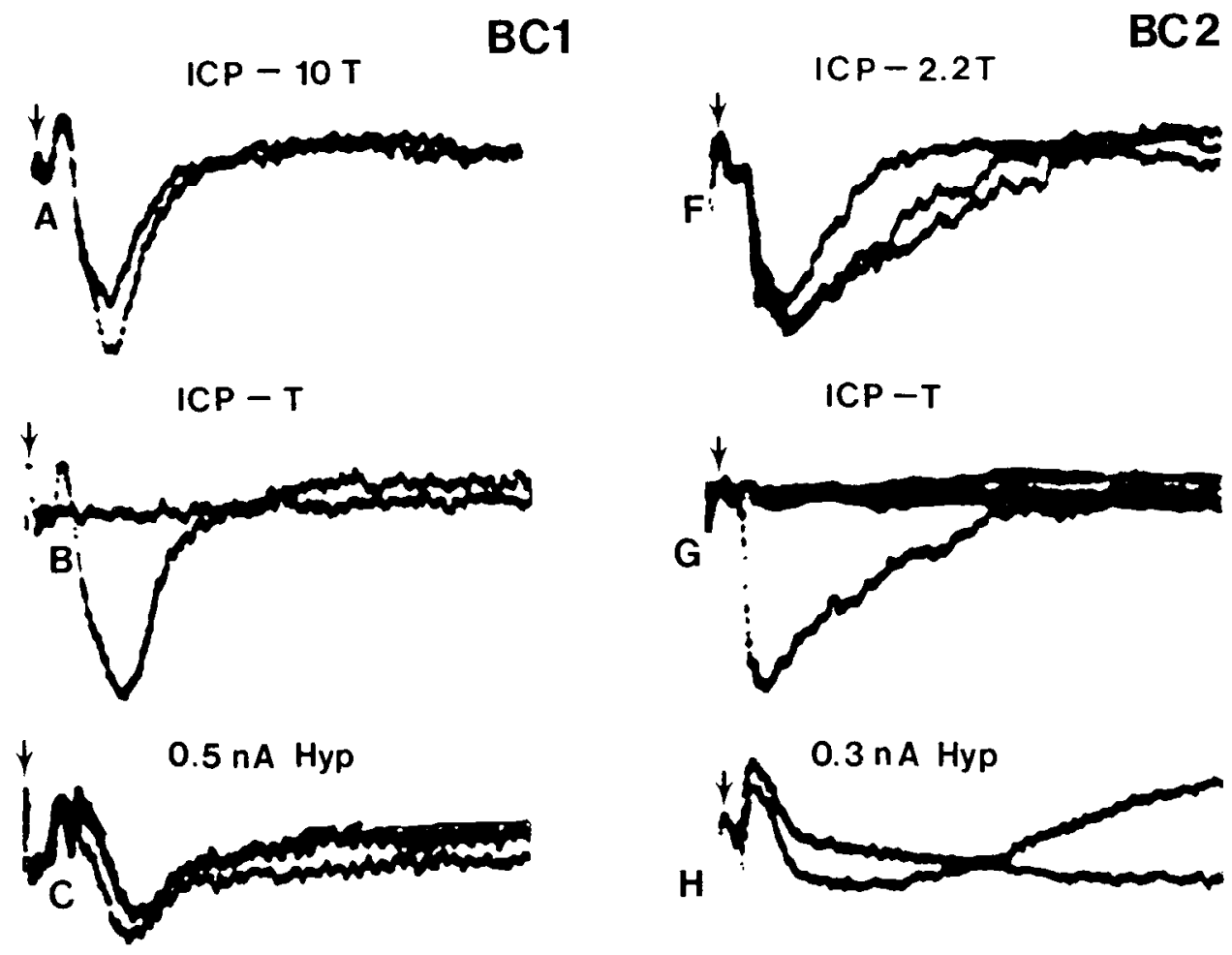

Figure 2. Physiological responses of 2 basket cells shown in Figure 1. The responses in Figure 2, $A-E$ are from $\mathrm{BC} 1$ (Fig. $1 A$ ) and in Figure 2, $F-I$ are from BC2 (Fig. $1 B$ ). Following stimulation of the ICP (arrows), the basket cells respond with an initial depolarization that is followed by a hyperpolarizing response $(A, F)$. At threshold intensities of stimulation $(B, G)$, the early depolarization and later hyperpolarization are all-or-none. The hyperpolarizing response is easily reversed by low-amplitude injections of hyperpolarizing current into the cell body $(C-E, H)$, and injections of depolarizing current increase its amplitude (I). The depolarizing response is also slightly increased following injections of hyperpolarizing current $(B-E)$.
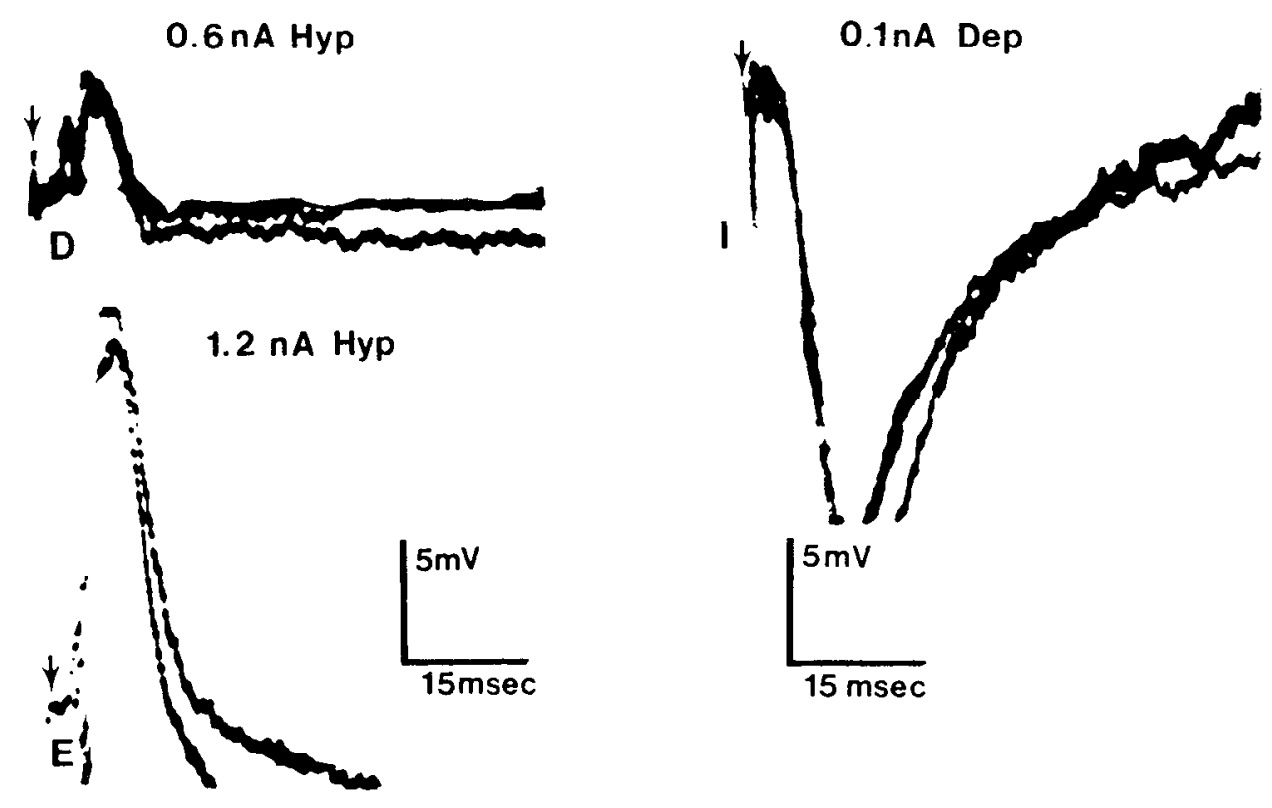

$\mu \mathrm{m}$ in diameter (mean diameter, $1.2, \mathrm{SD}, 0.23$ ) and are characterized by the presence of numerous mitochondria and pleomorphic synaptic vesicles. Because of the presence of the HRP reaction product, it is difficult to identify presynaptic membrane specializations characteristic of a synaptic site. However, for each profile, when followed through serial sections, there is a synaptic cleft, extracellular cleft material, and a slight increase in the density of the postsynaptic membrane (Fig. $7 \mathrm{~B}$, arrow). The cell in Figure 6 is contacted by 5 separate HRP-filled boutons (only 3 are shown), whereas the cell shown in Figure 7 is contacted by a single labeled terminal. However, this single terminal measured $1.3 \mu \mathrm{m}$ in diameter, was $4.5 \mu \mathrm{m}$ long, and had an extensive area of synaptic specialization with the basket cell body. In addition to HRP-labeled terminals, other profiles approximate the basket cell body. All profiles that were apposed to the basket cell body were classified into one of the following categories:

1. Fibers of passage (FP) - those that have no synaptic specializations and contain no vesicles (Fig. 6A, arrowheads).

2. Boutons (B) - those that have accumulations of vesicles but no distinct synaptic clefts or membrane densities (Fig. 6A, arrow). 


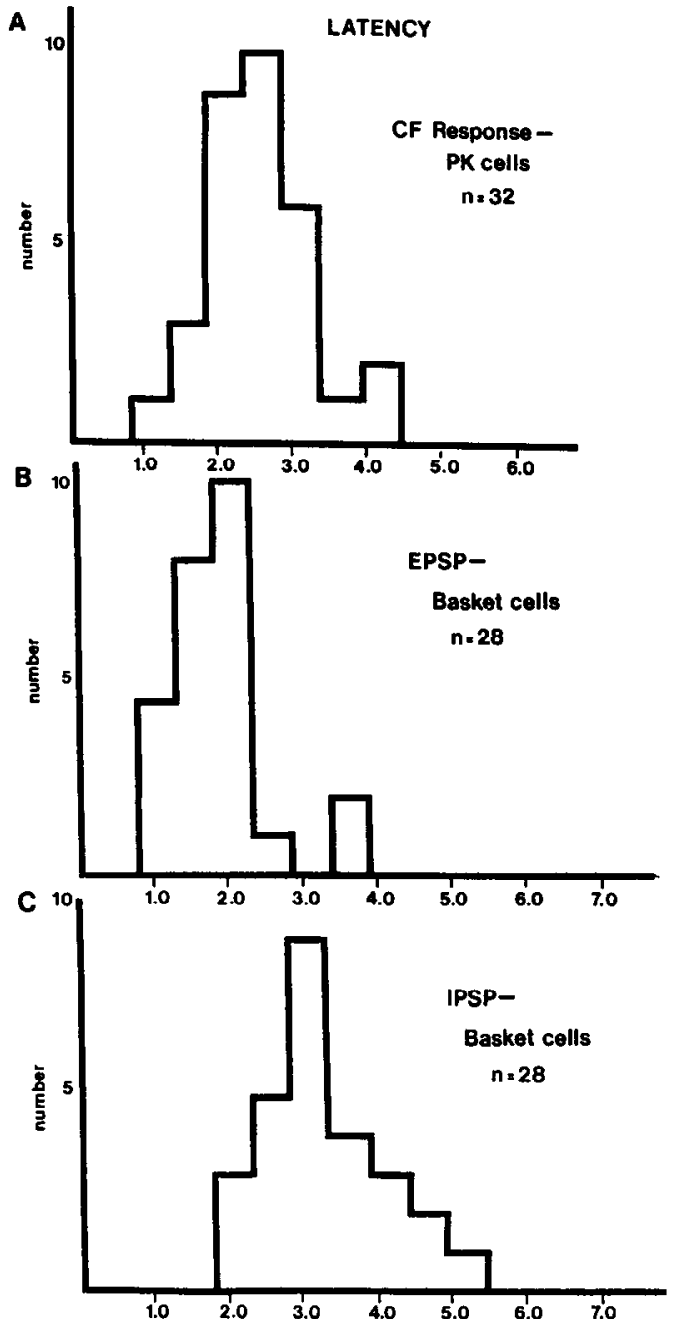

Figure 3. Histograms illustrating range of onset latencies in Purkinje cells and basket cells following stimulation of the ICP. The climbing fiber responses observed in Purkinje cells $(A)$ have the same latency as the initial depolarization of the basket cell response $(B)$. The basket cell IPSP $(C)$ occurs approximately $1 \mathrm{msec}$ after onset of the basket cell EPSP.

3. Synaptic boutons with round vesicles (RB) and membrane specializations characteristic of an active site (Fig. $7 C$, open block arrows).

4. HRP labeled profiles (LP) (Figs. 6, $A-D, 7, A-C$, solid block arrows).

No unlabeled terminals with cytological characteristics similar to those observed for the labeled terminals were found to approximate the basket cell body.

In this analysis, sections at $1.5 \mu \mathrm{m}$ intervals through each cell were selected. The perimeters of the various profiles described above were measured and tabulated with the aid of a Zeiss Videoplan. Data were compiled for profiles apposed to 2 basket cells with labeled terminals. The distributions of perimeter sizes for each profile type are illustrated in the histograms shown in Figure 8.

The most numerous profiles in apposition to the basket cell body are fibers of passage. These fibers (Fig. $8 A$ ) have a mean diameter of $0.3 \mu \mathrm{m}(\mathrm{SD} \pm 0.09)$ and an average perimeter of $1.13 \mu \mathrm{m}(\mathrm{SD} \pm 0.4)$. The majority of these fibers of passage appear to be parallel fibers. Profiles categorized as boutons with-
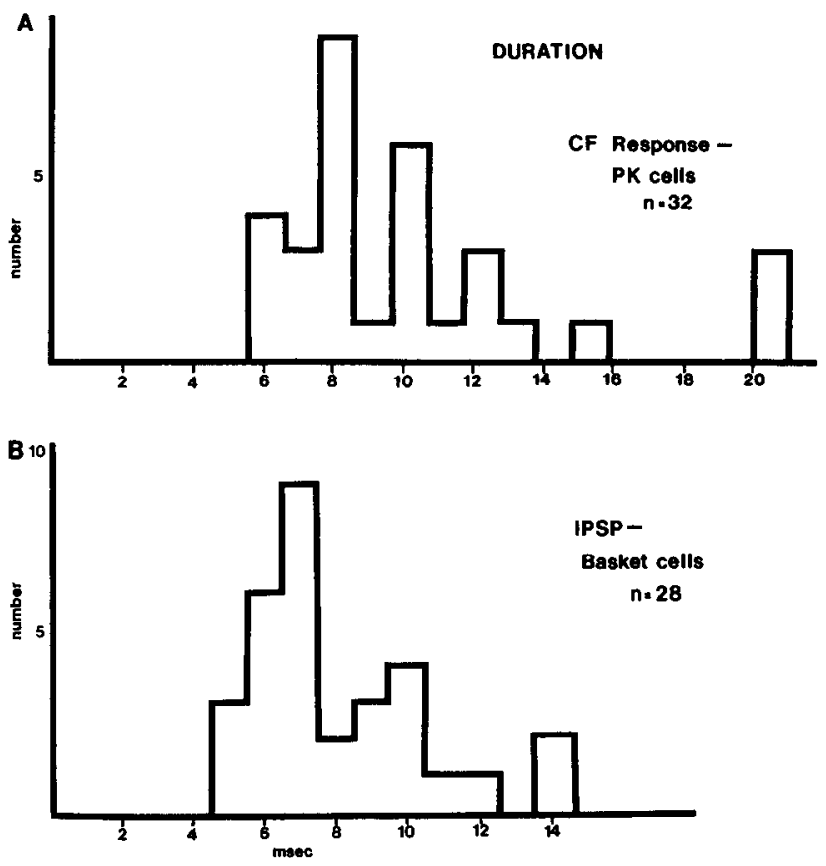

C

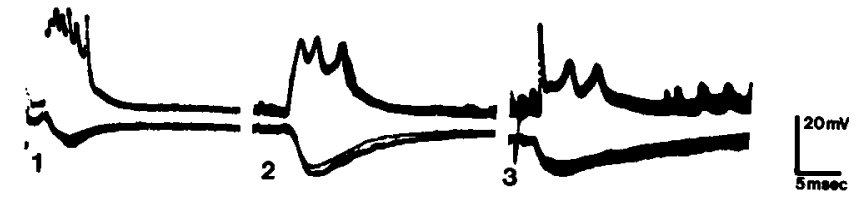

Figure 4. Histograms illustrating duration of the climbing fiber response and the basket cell IPSP. The duration of these 2 responses is very similar $(A, B)$. In $C 1-3$, the upper traces are climbing fiber responses of a Purkinje cell; the lower traces are basket cell responses obtained in the same experiments. Note that the basket cell IPSP begins just after the soma spike of the climbing fiber response is initiated. The IPSP rapidly increases to peak amplitude in approximately $2 \mathrm{msec}$, then gradually decreases. The time course of the response corresponds to the dendritic spike portion of the climbing fiber response.

out synaptic specializations (B) measure $0.56 \mu \mathrm{m}(\mathrm{SD} \pm 0.15)$ in diameter and have an average perimeter of $2.24 \mu \mathrm{m}(\mathrm{SD} \pm$ $1.04)$. Boutons with round synaptic vesicles ( $R B$ ) that form synapses with a basket cell somata are comparable in size to the B category. Many of the B and RB profiles have cytological characteristics of terminals derived from parallel fibers. The labeled terminals are the largest profiles in contact with the basket cell, having an average diameter of $1.2 \mu \mathrm{m}(\mathrm{SD} \pm 0.26)$ and perimeter of $4.2 \mu \mathrm{m}(\mathrm{SD} \pm 1.1)$. In the present analysis, no profiles with the cytological features of a climbing fiber terminal, i.e., a dark cytoplasmic matrix packed with round synaptic vesicles, were found related to the somata of basket cells. In addition, no unlabeled terminals were found with pleomorphic vesicles, multiple mitochondria, and a dark cytoplasmic matrix; these cytological features are characteristic of Purkinje cell terminals. Thus, the only identified inhibitory type of synapse that was seen in contact with the somata of these basket cells were from labeled Purkinje cell collaterals.

\section{Discussion}

The axon of the basket cell forms a complex arbor that surrounds the soma and initial segment of the Purkinje cell. Functionally, the basket cell represents an inhibitory input to the Purkinje 


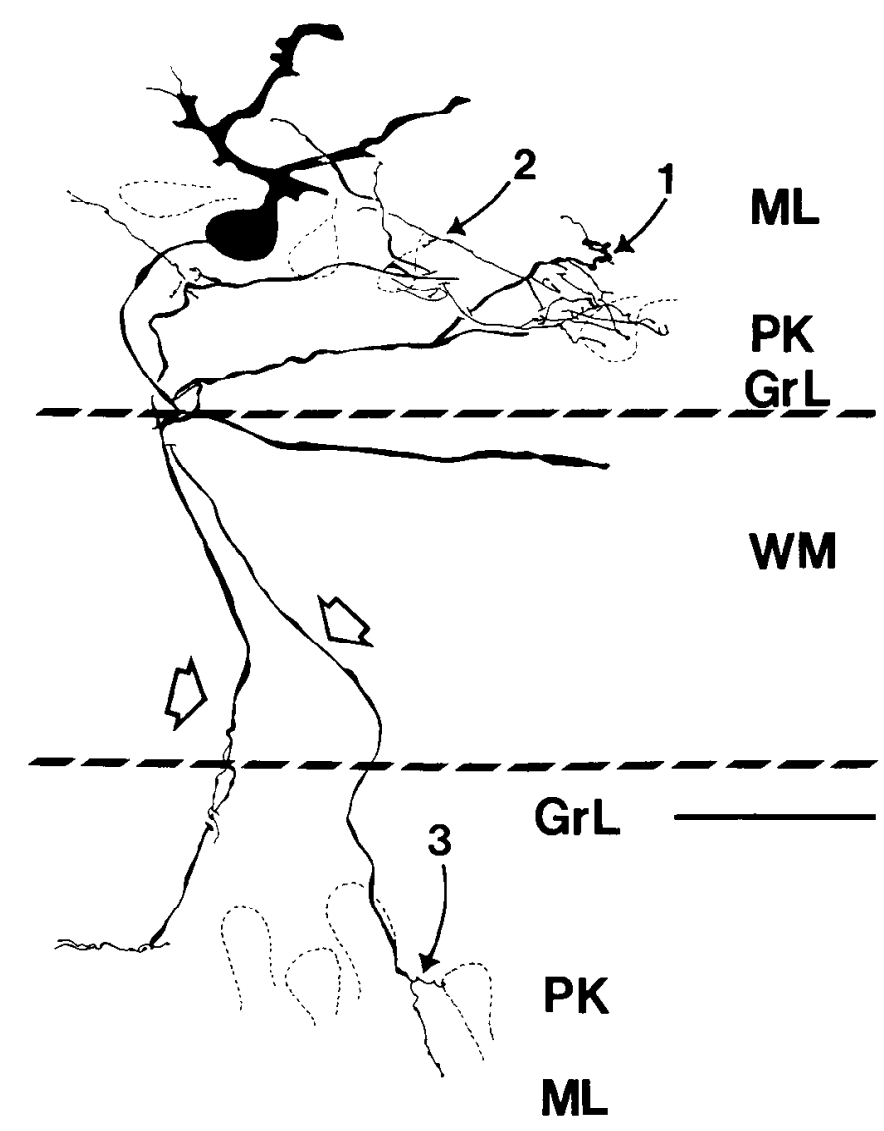

Figure 5. Serial section reconstruction of a Purkinje cell that was intracellularly labeled with HRP. The open block arrows indicate 2 branches that terminate in the Purkinje cell layer and molecular layer (curved arrow 3) on the other side of the folium. The curved arrows labeled $I$, 2 , and 3 indicate portions of the collateral plexus that were analyzed by electron microscopy. Scale bar, $100 \mu \mathrm{m} . M L$, molecular layer; $P K$, Purkinje cell layer; $G r L$, granule cell layer; $W M$, white matter.

cell; thus any circuits that alter basket cell firing will have a direct influence on cortical output as relayed by the Purkinje cell.

Previous studies (Bloedel and Roberts, 1969, 1971; Llinás and Precht, 1969; Bloedel et al., 1972) have used physiological techniques to analyze the interactions between Purkinje cells and basket cells in the cerebellar cortex of the cat. The conclusions from these earlier studies are that these cells are inhibitory to each other. However, a given basket cell probably does not interact with the Purkinje cell that inhibits it (Bloedel and Roberts, 1969; unpublished observations). The present report is the first study to usc a combincd intraccllular recording/staining paradigm to show that the Purkinje cell-basket cell interaction is unitary. The data obtained in this study suggest that convergent somatic inputs from different Purkinje cells are not involved in the inhibition of individual basket cells. The physiological properties of the IPSP and the electron microscopic analysis indicate that the inhibition is mediated by synaptic contacts on the basket cell somata that are derived from a single Purkinje cell. However, neither the physiological nor the anatomical findings of this study rule out the possibility that basket cells may receive separate axodendritic synapses from the same or different Purkinje cells.

Previous studies (Mugnaini, 1972; Palay and Chan-Palay, 1974; Jeager et al., 1988) have suggested that the recurrent col- laterals of Purkinje cells contact basket cell somata. In the present study, 2 basket cells that received input from an HRPlabeled Purkinje cell were serially sectioned to determine if there was convergence of input onto the somata from the recurrent collaterals of more than one Purkinje cell. The ultrastructural analysis confirmed the findings of the physiological study in that only labeled collaterals contacted the somata of these neurons. No profiles with cytological characteristics comparable to those of the labeled terminals synapsed with the basket cell. Thus, the anatomical substrate for the observed physiological responses is present. However, a point that must be addressed is whether there are a sufficient number of contacts to produce the largeamplitude hyperpolarization observed in this study. One of the serially sectioned basket cells received input from 5 different boutons, whereas the other was contacted by a single labeled terminal that had an extensive area of synaptic contact. These multiple and extensive inputs, located on the somata of the basket cell are likely adequate for induction of the large-amplitude hyperpolarization. Further, no unlabeled boutons with cytological characteristics of an inhibitory synapse (e.g., pleomorphic vesicles) were found in apposition to the basket cell body. Thus, there does not appear to be another source of inhibition to the soma of basket cells.

The initial EPSP may also be derived from a single neuron on the basis of the all-or-none response observed following stimulation of the inferior cerebellar peduncle. The source of the unitary EPSP was not determined in this study. Several lines of evidence suggest that it may be derived from a collateral of a climbing fiber. First, the stimulating electrodes, placed in the inferior cerebellar peduncle, readily elicit climbing fiber responses in Purkinje cells at comparable latencies. Mossy fibers, that should also be activated by the stimulating electrodes do not seem to have a major effect in this preparation. The short latency to onset of the EPSP (1-3 msec) indicates that the input is monosynaptic, as opposed to the disynaptic mossy fiber-parallel fiber system. A second argument for a climbing fiber origin for the initial EPSP is the all-or-none nature of the response. Basket cell dendrites (Mugnaini, 1972; Palay and Chan-Palay, 1974) and somata are contacted by numerous parallel fibers. Therefore, a graded response to changes in stimulus intensity would be expected if the mossy fiber-parallel fiber pathway was the source of the EPSP. The one-to-one relationship between Purkinje cells and a climbing fiber derived from neurons in the inferior olivary complex is well established. It is possible that a similar relationship may exist between the inferior olive and the basket cell. These findings suggest that there may be comparable specificity in the climbing fiber-basket cell relationship as there is between this afferent system and the Purkinje cell. An even greater specificity in the olivocerebellar system will be revealed if experimental evidence demonstrates that a single climbing fiber activates a basket cell, as well as the Purkinje cell that inhibits it.

The IPSP elicited in basket cells following stimulation of the inferior cerebellar peduncle appears to be temporally related to the climbing fiber response recorded from a Purkinje cell. The hyperpolarization has a latency that is comparable to the dendritic spike portion of the climbing fiber response and the duration of the basket cell's IPSP is directly proportional to the duration of the secondary dendritic spikes (Llinás and Sugimori, 1980) of the climbing fiber response. It is unknown, at present, if a comparable response is elicited in basket cells following parallel fiber activation of a Purkinje cell. That is to say, is 

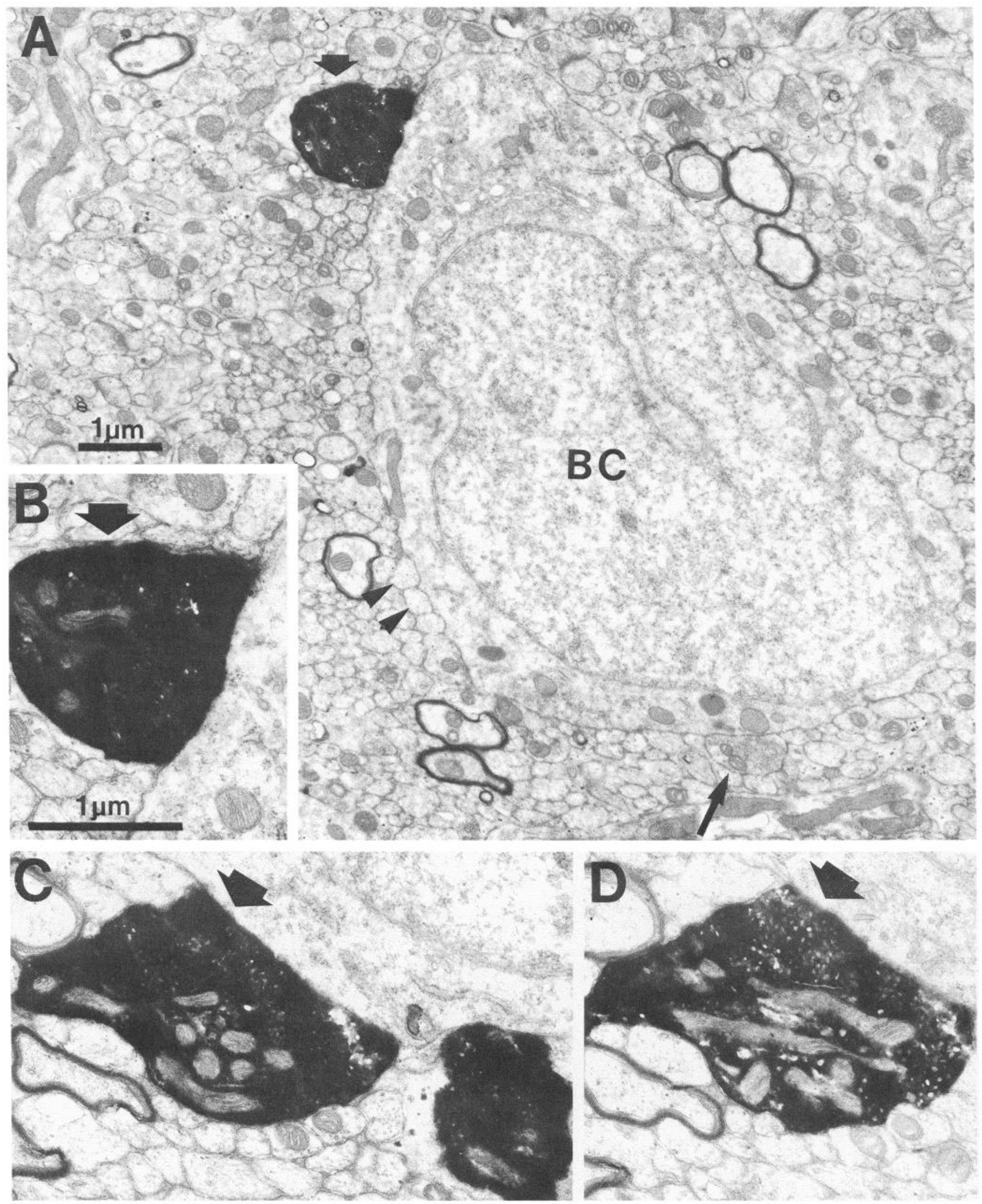

Figure 6. Electron micrographs illustrating relationships between varicosities (solid block arrows) indicated by curved arrow 1 in Figure 5 and a basket cell body. The profile shown in $B$ (solid block arrow) is a higher-magnification serial section of the profile shown in $A$ (solid block arrow). The profiles shown in $C$ and $D$ (solid block arrows) are serial sections through another labeled terminal that contacts the same basket cell, and a third labeled profile is seen in $C$. The varicosities are characterized by the presence of pleomorphic vesicles and numerous mitochondria. The other profiles that approximate the basket cell body include small-diameter fibers of passage (arrowheads) and a bouton that contains round vesicles (arrow). Scale bar in $B$ also applies to $C$ and $D$. 


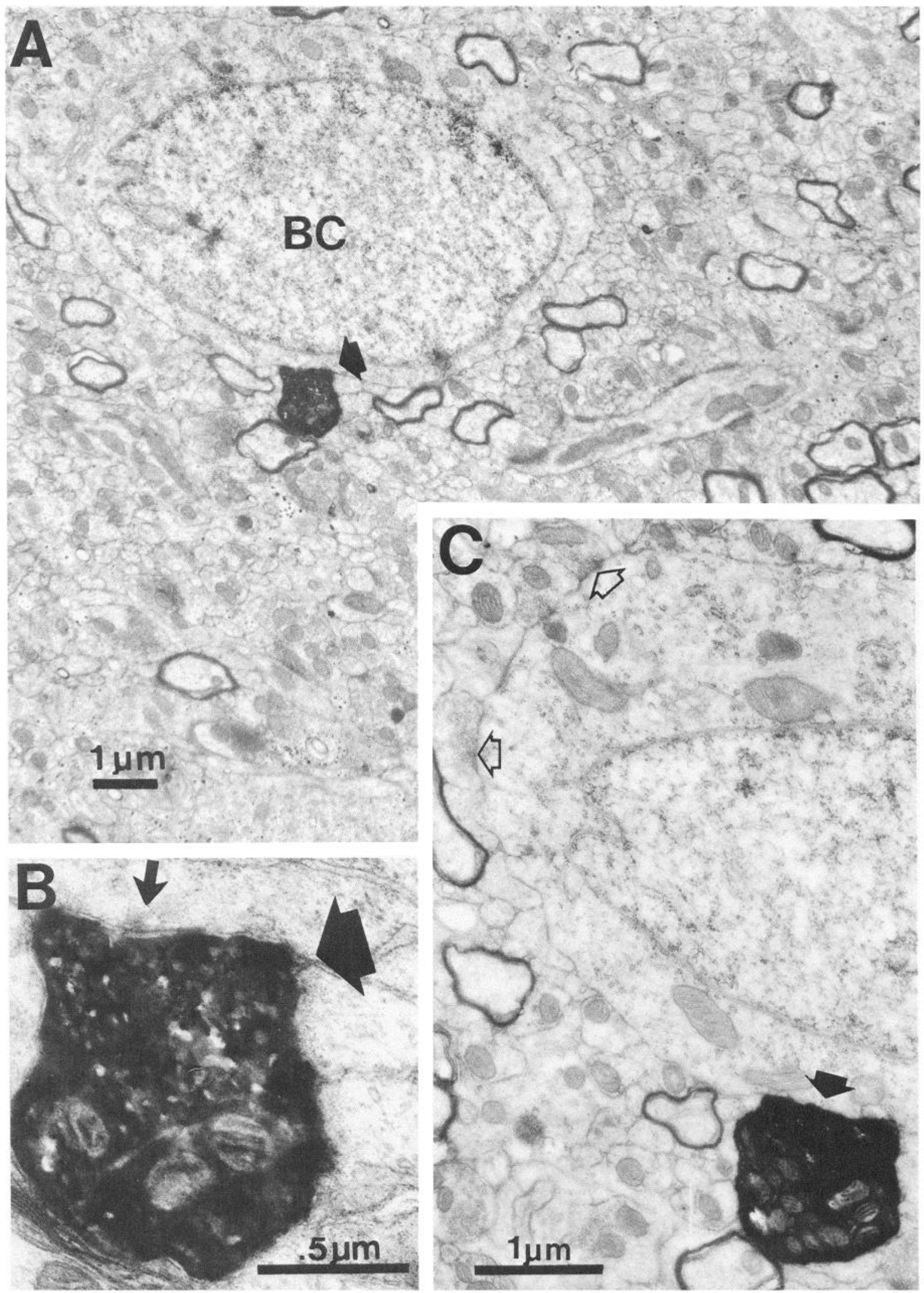

Figure 7. Electron micrograph illustrating the synaptic relationships between the varicosities indicated by curved arrow 2 in Figure 5 and a basket cell. The HRP-labeled bouton shown in $A$ (solid block arrow) is shown at higher magnification in $B$. The arrow indicates increased density of the postsynaptic membrane and a synaptic cleft. $C$, Same labeled bouton (solid block arrow) in a serial section. The open block arrows indicate small unlabeled profiles that contain round vesicles and form synaptic junctions with the basket cell body. 
simple spike activation of a Purkinje cell able to elicit on allor-none IPSP in a basket cell and, if so, is the duration comparable to that of the simple spike? Future studies will allow us to determine if the observed responses are inherent to the basket cell membrane or if they are directly related to specific afferent activation of Purkinje cells.

The present study, has shown that a Purkinje cell activated by a climbing fiber blocks the excitatory input to the basket cell and induces a prolonged inhibition of the neuron. The observation that the duration of the basket cell IPSP is comparable to the time course of the climbing fiber response suggests that the axon collateral of the Purkinje cell is activated throughout the climbing fiber response. This is in contradiction to some studies that have suggested that the Purkinje cell axon is inactivated by the powerful climbing fiber response (Granit and Phillips, 1956; Colin et al., 1980).

\section{Functional considerations}

The majority of physiological studies (Eccles et al., 1967; Bloedel and Roberts, 1969, 1971; Llinás and Precht, 1969; Bloedel et al., 1972) have focused on the inhibitory effect of basket cells on their target neurons. Llinás and Precht (1969) suggested that one of the functions of the recurrent collaterals of Purkinje cells is the modulation of inhibitory interneurons of the cerebellar cortex. This regulation would be most effective if the synapses occur in a somatic position, as those described in this study. Recent studies (Ebner and Bloedel, 1981a, b; Bloedel et al., 1983; Bower and Llinás, 1983; Sasaki and Llinás, 1985; Ebner and Bloedel, 1988; Tam et al., 1988) have suggested that Purkinje cells aligned in sagittal strips have a tendency to fire in synchrony. Thus, based on the findings of the present study, a specific population of basket cells, located within $200-250 \mu \mathrm{m}$ of the activated Purkinje cells in the transverse plane, would be inhibited; these dimensions represent the average transverse extent of the recurrent collateral plexus (Bishop and O'Donoghue, 1986; O'Donoghue et al., 1986). The inhibition of these basket cells would be solely dependent on activation of a particular sagittal ensemble of Purkinje cells, and thus, is likely related to a specific olivocerebellar input. Neurons that are normally inhibited by these basket cells would be facilitated by disinhibition. In this way, additional sagittal arrays of Purkinje cells could be recruited in response to a given input. The fact that convergence of Purkinje cell input is not required increases the specificity in this circuit and ultimately in motor control.

Oscarsson (1979) and Ito (1984) have suggested the working unit of the cerebellum is a corticonuclear complex; this is defined as a population of Purkinje cells, and the deep nuclear neurons to which they project. This proposed unit of cerebellar function docs not include a consideration of the effect of local circuitry on the Purkinje cell and the role these circuits play in modifying the output of the Purkinje cell. The unitary nature of the Purkinje cell-basket cell interaction indicates that specific populations of interrelated cortical neurons may serve to integrate information for a specific corticonuclear complex.

\section{References}

Bishop, G. A. (1982) The pattern of distribution of the local axonal collaterals of Purkinje cells in the intermediate cortex of the anterior lobe and paramedian lobule of the cat cerebellum. J. Comp. Neurol. 210: 1-9.

Bishop, G. A. (1988) A quantitative analysis of the recurrent collaterals derived from Purkinje cells in zone $\mathrm{x}$ of the cat's vermis. J. Comp. Neurol. 247: 17-31.
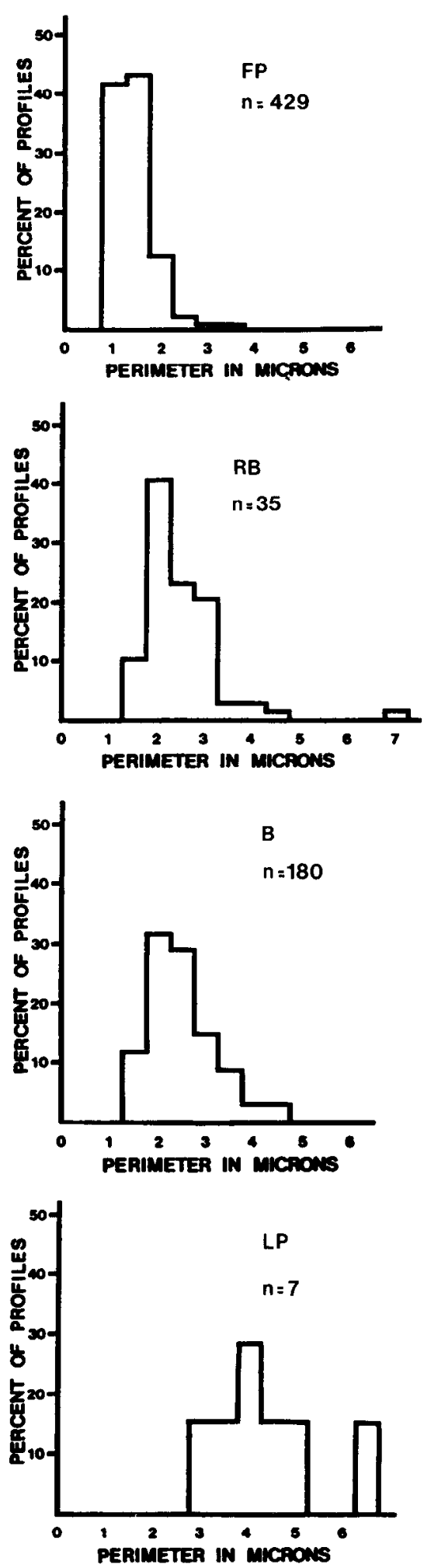

Figure 8. Histograms comparing the distributions of size for the perimeters of the various profiles in contact with basket cell bodies. $F P$, fibers of passage; $B$, boutons that do not form synaptic junctions; $R B$, boutons that contain round synaptic vesicles and form synaptic junctions; $L P, H R P$-labeled profiles. No unlabeled terminals with cytological features comparable to the labeled profile are found around basket cells that are contacted by labeled collaterals. 
Bishop, G. A., and J. S. King (1982) Tracing neural connections with horseradish peroxidase histochemistry by intracellular injection. In Tracing Neural Connections With Horseradish Peroxidase, M.-M. Mesulam, ed., pp. 185-247, Wiley, London.

Bishop, G. A., and D. L. O'Donoghue (1986) Heterogeneity in the pattern of distribution of the axonal collaterals of Purkinje cells in zone $b$ of the cat's vermis: An intracellular HRP study. J. Comp. Neurol. 253: 483-499.

Bishop, G. A., R. A. McCrea, and J. S. King (1980) An analysis of the morphology and cytology of HRP labeled Purkinje cells. Brain Res. Bull. 5: 563-574.

Bloedel, J. R., and W. J. Roberts (1969) Functional relationship among neurons of the cerebellar cortex in the absence of anesthesia. J. Neurophysiol. 32: 75-84.

Bloedel, J. R., and W. J. Roberts (1971) Action of climbing fibers in the cerebellum of the cat. J. Neurophysiol. 34: 17-31.

Bloedel, J. R., R. S. Gregory, and S. H. Martin (1972) Action of interneurons and axon collaterals in cerebellar cortex of a primate. J. Neurophysiol. 35: 847-863.

Bloedel, J. R., T. J. Ebner, and Q.-X. Yu (1983) Increased responsiveness of Purkinje cells associated with climbing fiber inputs to neighboring neurons. J. Neurophysiol. 50: 220-239.

Bower, J., and R. Llinás (1983) Simultaneous sampling of the responses of multiple, closely adjacent, Purkinje cells responding to climbing fiber activation. Soc. Neurosci. Abstr. 9: 607.

Colin, F., J. Manil, and J. C. Desclin (1980) The olivocerebellar system. I. Delayed and slow inhibitory effects: An overlooked salient feature of cerebellar climbing fibers. Brain Res. 187: 3-27.

Ebner, T. J., and J. R. Bloedel (1981a) Temporal patterning in simple spike discharge of Purkinje cells and its relationship to climbing fiber activity. J. Neurophysiol. 45: 933-947.

Ebner, T. J., and J. R. Bloedel (1981b) Correlation between activity of Purkinje cells and the modification by natural peripheral stimuli. J. Neurophysiol. 45: 948-961.

Ebner, T. J., and J. R. Bloedel (1988) Climbing fiber afferent system: Intrinsic properties and role in cerebellar information processing. In New Concepts in Cerebellar Neurobiology, J. S. King, ed., pp. 371386, Liss, New York.

Eccles, J. C., M. Ito, and J. Szentagothai (1967) The Cerebellum as a Neuronal Machine, Springer-Verlag, New York.

Fox, C. A., D. E. Hillman, K. A. Seigesmund, and C. R. Dutta (1967) The primate cerebellar cortex: A Golgi and electron microscopic study. Prog. Brain Res. 25: 174-225.
Granit, R., and C. G. Phillips (1956) Excitatory and inhibitory processes acting upon individual Purkinje cells of the cerebellum in cats. J. Physiol. (Lond.) 133: 520-547.

Ito, M. (1984) The Cerebellum and Neural Control, Raven, New York. Jeager, C. B., R. Kapoor, and R. Llinás (1988) Cytology and organization of rat cerebellar organ cultures. Neuroscience 26: 509-538.

King, J. S., and G. A. Bishop (1982) The synaptic features of horseradish peroxidase-labeled recurrent collaterals in the ganglionic plexus of the cat cerebellar cortex. J. Neurocytol. 11:867-880.

Lemkey-Johnston, N., and L. M. H. Larramendi (1968) Types and distribution synapses upon basket and stellate cells of the mouse cerebellum: An clcctron microscopic study. J. Comp. Neurol. 134: 73-112.

Llinás, R., and W. Precht (1969) Recurrent facilitation by disinhibition in Purkinje cells of the cat cerebellum. In Neurobiology of Cerebellar Evolution and Development, R. Llinás, ed., pp. 619-627, American Medical Assoc., Chicago.

Llinás, R., and M. Sugimori (1980) Electrophysiological properties of in vitro Purkinje cell somata in mammalian cerebellar slices. J. Physiol. (Lond.) 305: 171-195.

Mugnaini, E. (1972) The histology and cytology of the cerebellar cortex. In The Comparative Anatomy and Histology of the Cerebellum: The Human Cerebellum, Cerehellar Connections and Cerebellar Cortex, O. Larsell and J. Jansen, eds., pp. 201-264, University of Minnesota Press, Minneapolis.

O'Donoghuc, D. L., T. L. Blake, J. S. King, and G. A. Bishop (1986) Recurrent axon collaterals of Purkinje cells in zone $\mathrm{cl}$ of the cat cerebellum. Anat. Res. 214: 92A.

Oscarsson, O. (1979) Functional units of the cerebellum-sagittal zones and microzones. Trends Neurosci. 2: 143-145.

Palay, S. L., and V. Chan-Palay (1974) The Cerebellar Cortex: Cytology and Organization, Springer-Verlag, New York.

Ramón y Cajal, S. (1911) Histologie du systeme nerveux de l'homme et des vertebres, Maloine, Paris.

Sasaki, K., and R. Llinás (1985) Evidence for dynamic electrotonic coupling in mammalian inferior olive in vivo. Soc. Neurosci. Abstr. 11: 181 .

Tam, D. C., T. J. Ebner, and C. K. Knox (1988) Conditional crossinterval correlation analyses with applications to simultaneously recorded cerebellar Purkinje neurons. J. Neurosci. Methods 23: 23-33. 